\title{
CONTRIBUTIONS TO THE MORPHOLOGY OF THE BRAIN OF BONY FISHES.
}

\author{
C. L. And C. Judson Herrick. \\ I. - SILURIDA. - With Plate XVII. \\ C. JUDSON HERRICK.
}

The family Siluridæ, comprising the cat fishes and bullpouts, forms a very convenient starting point for a discussion of the brain of the teleosts. It is a very close family, at least as far as our inland fresh-water forms are concerned, and at the same time it is distributed in great abundance over the entire North American Continent with considerable diversity of habitat.

Of all the Teleostei the Siluridx, according to Prof. Cope, (') are more closely related in internal structure to the gars and other ganoids. The brain, however, is as distinctly teleostean as that of any other fish examined and shows very little evidence of any close relationship with the ganoid fishes. On the other hand, the elongation of the olfactory crura, the structure of the cerebrum, the extrusion of the cerebellum and the form of the medulla all suggest affinities with the more highly specialized teleosts, while the brain of some of the other bony fishes, particularly the mud-eating fishes, Hyodon, Dorosoma, etc., has a very pronounced reptilian aspect. Judging from brain characters alone, the

I Fide Jordan and Gilbert, "Manual," p. y5. 
Siluridæ should be placed among the most highly specialized bony fishes, though this, of course, does not necessarily involve a position high in the scale, phylogenetically con. sidered.

The present contribution is based upon the study of dissections and histological preparations of such species of Siluridz as are most accessible in the Ohio Valley., viz., Amiurus catus gill, Pilodictis olivaris Gill and Jordan, Ictalurus punctatus Jordan, and Ictalurus lacustris Gill and Jordon. The adult brains of these species are so nearly alike that it would be difficult to distinguish them externally, and in the following descriptions the statements apply to all of them unless otherwise expressly indicated. In the case of some of our large river cats especially, and probably of the other species also, the brain practically ceases to grow when the fish attains a moderate size, even though the weight of the body may afterward increase many fold. A specimen of the mud cat, Pilodictis olivaris, for instance, weighing twenty-one pounds, had a brain which, when hardened, could scarcely be distinguished by careful measurements from that of another specimen weighing less than five pounds. The cranial cavity, however, enlarges more nearly in proportion to the size of the head. In large specimens it is more than twice the size of the brain, which lies in the ventral and caudal portion. In the remaining space an oily arachnoid tissuc is closely packed around the emerging nerves. In smaller specimens the brain is much larger in proportion to the head until in individuals one inch long it fills the entire cranial cavity and, in fact, almost the entire head.

Measurcments.-The following measurement are taken from an alcoholic brain of Pilodictis olizaris. Other measurements in the text refer to the same specimen. This fish was 40 $\mathrm{cm}$. long, and would weigh about four pounds. The measurements, however, would be almost equally exact for the brain of a specimen weighing twenty pounds: Length of brain from end of cerebrum to exit of dorsal root of vagus, $17 \mathrm{~mm}$; 
length of cerebrum, $6 \mathrm{~mm}$; width of cerebrum, $7.5 \mathrm{~mm}$; width of optic lobes, io mm.; width of cerebellum, I1.25 $\mathrm{mm}$; length of cerebellum in the median median line, 8.5 $\mathrm{mm}$.

Cranial Nires.-Compared with the size of the brain, the cranial nerves are enormous, much larger than in any other fish which has come to our notice. This is a function, doubtless, of the enormous size of the head in the cat fishes. The olfactory nerves are very short, passing directly from the olfactory lobes into the nasal cavities in numerous separate bundles. The optic nerves are long, passing out, in large fish, for several centimetres parallel to the olfactory crura, then diverging at at acute angle to the orbits. They arise from the ventral surface of the thalamus, immediately cephalad of the hypoaria, are quite distinct from each other at the origin and remain so throughout, crossing, however, below the cerebrum. They are not, at first, cylindrical, but very strongly flattened dorso-ventrally. The other cranial nerves may be conveniently divided after Gegenbaur, into two groups, the trigeminus group and the vagus group. In hoth of these groups the relations are greatly complicated, not only by the large size of some of the ncrve roots, but by the presence of plexi. Only the more important of these arc noted, and in the peripheral distribution many of the smaller branches are omitted.

In the trigeminus group the fifth is of supreme importance, and absorbs many of the others. The third arises as a single strand under the caudo-lateral angle of the hypoaria, passes into the fifth and loses its identity completely (Plate XVII, Fig. 4, III). 'The fourth is minute. It arises from the caudal end of the optic lobe and also passes out with the fifth. 'The fifth is larger than all of the other cranial nerves combined, and passes out of the cranial cavity by no less than four distinct foramina. 'These are indicated in approximately their relative positions in Platc XVIl, Fig. 5. For convenience of description the various branches of the fifth will he 
numbered as in the figure last referred to and treated successively. The branch $V_{1}$ is discrete from the others and passes farther dorsad to a separate foramen, $F_{1}$, having previously divided, giving off a large branch ventrad which passes through the foramen $F_{a}$. Before this division it receives a small ramus from $V_{i}$, another from $V_{i}$, and gives one to the combined trunk of $V_{\text {: }}$ and VII. The dorsal branch of $V_{1}$ gives off a small twig before entering its foramen which passes dorsad, then cephalad between the frontal bones. After passing through the foramen it takes its course not far from the median line superficially, giving off various fibres to the frontal region, to terminate in the premaxillary. The more ventral division of $V_{1}$, after passing through the lower foramen, $F_{1}$, is wrapped up with the fibres of $V_{s}$ without, however, losing its separate identity, receives at least two separate small strands from $V_{y}$, and passes through the lower part of the orbit, giving off several branches to the infraorbital region and the region behind and above the angle of the mouth. The branch $V_{:}$is also nearly discrete to its origin. After passing through the foramen $F_{2}$, it gives off the two branches above referred to, several small twigs to the frontal region, two large branches to the posterior nasal barbel, and terminates in several branches in the premaxillary not far from the terminus of the dorsal part of $V_{1}$. It also gives off a considerable branch which supplies the supraorbital region and passes on to the anterior nasal region. The branch $V_{:}$is nearly distinct from the two preceding, but more closely united with $V_{\text {: }}$ until after they leave their foramen. It gives oft a considerable ramus soon after leaving the foramen, which sinks down to the roof of the mouth and terminates in the dental cavity of the premaxillary. The major part of this branch passes farther laterad through the orbit, giving two large rami to the barble at the angle of the mouth and others to the regions adjacent. Another branch which passes through the foramen $F_{:}$is $V_{+}$, which connects by means of a small ramus with $V_{3}$. After leaving the fora- 
men it divides into two. A smaller branch turning caudo. laterad passes to the masseter. The remainder passes through the orbit to the angle of the mouth and infra-maxillary region. The remaining fibres, which pass through the foramen $F_{z}$, are those of $V_{\text {: }}$ and VII, which are inseparably united for several centimetres. This trunk receives, in addition to the fibres from $V_{1}$ and $V_{+}$, referred to above, a small fascicle from $V_{15}$. After leaving the foramen a considerable branch is given off from the cephalic division which dips down and passes caudo-laterad to the depressor operculi. The branches $V_{\text {; }}$ and VII subsequently partially reunite before their final separation. This plexus may serve the function of a chorda tympani. The more cephalic branch, $V_{b}$, is considered to be the homologue of the inferior maxillary nerve. It gives off a few small tibres to the ental surfacc of the masseter and then divides. The more superficial division passes cephalad to the infra-maxillary region. The deeper division passes through a foramen in the articulare inferius suspensorii maxillæ (of Meckel) and again divides into a dentary branch penetrating the end of the inferior maxillary into its dental cavity and a mylo-hyoid branch which passes by the end of the inferior maxillary, then cephalad on the ventro-mesal surface of the latter to the inferior barbels, two branches being given to each barbel. Ramus VII, which is considered to be the homologue of the facial nerve, after separating from $V_{:}$, passes laterad, giving off a twig to the levator operculi. Passing then to the ventral surface, it supplies the muscles of that region, apparently those concerned chiefly with deglution. The carotid plexus, if present, is probably all intra-foraminal. With reference to the first four divisions of the fifth, homologies cannot be pushed very far; and yet it seems legitimate to consider that the more dorsal division of $V_{1}$ and $V_{:}$are, roughly speaking, homologous with the orbito-nasal (of Parker), the rest of $V_{1}, V_{3}$, and $V_{4}$ with the superior maxillary. Two important divisions of the fifth remain to be considered. The small branch $V_{\text {" }}$ 
springs from the base of $V_{\text {; }}$ very near its origin and passes cephalo-dorsad through a separate foramen, $F_{\text {, }}$, thence laterad to the opercle, superficially. Before entering its foramen it sends a very small twig cephalad to ramify in the frontal bone near the median line. $V_{;}$is one of the largest separate branches of the fifth nerve. Its apparent origin is not from the medulla, but from the roots of the other divisions. It passes dorso-caudad through a foramen, $F_{4}$, situated over the caudal end of the medulla, thence caudad superticially near the median line the entire length of the body. It appears to partake of the function of the nerve of the lateral line. (iasser's ganglion is obviously developed on this branch alone. The microscope, however, shows elongated bands of ganglion cells between the strands of the other branches also. The sixth nerve could not be separately distinguished. The auditory nerve springs from the medulla immediately caudad of the trigeminal by several roots which are united into a broad, flat band. The cephalic and caudal portions supply the semi-circular canals, the middle portion the otolithic sac.

In the vagus group the ninth and tenth nerves are quite distinct. The ninth arises immediately caudad of the eighth and closely associated with it. After sending a branch to communicate with the ventral root of the vagus it divides, one branch going to the opercle, the other to the first gill. One or two small branches arise near the medulla and pass caudad. Their connections were not discovered. 'The tenth arises by two large roots, dorsal and ventral, which combine into a ganglion outside the foramen. Cephalad, there branch off from this ganglion nerves to the several gills, one branch to the first and second, another to the second and third, and another to the third and fourth. Each gill thus receives two distinct nerves. l'assing caudad, there is a large branch which divides, one portion supplying the levator of the pectoral fin, the other the depressor of the pectoral fin. From the latter arises a small cutaneous branch to the post- 
opercular region. Arising from the ganglion of the vagus immediately dorsad of the last is a very small fibre passing to the lower pharyngeal region. Farther dorsad is the visceral branch of the vagus. This gives a small branch to the middle of the fourth gill and a larger one to the organs of the thorax. The main trunk passes caudad and spreads out over the stomach, mesentary, etc. The largest, division of the vagus nerve is the nerve of the lateral line. It communicates by a delicate plexus with the nerves of the muscles of the pectoral fin and the cutaneous nerve connected with them, then passes caudad superficially along the lateral line for the whole length of the body. The spinal accessory nerve cannot be separately distinguished. The first spinal nerve, which might, perhaps, with equal propricty be called the twelfth cranial nerve, arises behind the medulla by two roots, dorsal and ventral. The latter is considerably farther cephalad than the former. The two roots remain distinct until after they pass through their foramen (Plate XVII, Fig. $5, n . s p$ ).

Rhinencephalon.-The olfactory lobes in the adult are in immediate proximity to the nasal cavities, and therefore far distant from the rest of the brain. In large specimens the olfactory crura would thus be more than fifteen centimetres long, while the olfactory nerves would be only a few millmetres. In very young specimens one inch long the brain is so large that it fills the whole front part of the head, and the olfactory lobes are in their usual position, closely appressed to the cerebrum. Compare Plate XVII, Fig. 2, with Fig. 3. Each lobe is sub-spherical, three millimetres in diameter, attached to the crus on the caudal aspect, with the fibres of the olfactory nerve springing from the opposite side. The internal structure is very much as in reptilia. Ectad there is a glomerulary zone which is well developed, though not so much as in Iyodon. Within this are specitic olfactory cells irregularly and sparsely distributed in a single series. They are fusiform to Hask-shaped, with the apices usually directed peripherally. The centre of the lobe contains small 
dense cells resembling Deiter's cells. There is an olfactory ventricle which extends from the cerebral ventricle the whole length of the crus and well out into the lobe, though not to its centre. It lies in the dorsal part of the lobe and retreats farther dorsad as the lobe passes into the crus. In the crus itself all of the fibres lie ventrad of the ventricle which is bounded laterally, as well as dorsally, merely by a membrane. The entire cavity is lined with epithelium. This membrane is continuous caudad with the pallium of the cerebrum and, with the epithelium of the ventricle, is the apparent homologue, using Prof. Wilder's terminology, of the pes, while the fibrous portion of the crus and the body of the lobe constitute the pero of the olfactory. In the olfactory crus the fibres are gathered into numerous bundles which are separated by layers of small spherical cells. The crus, upon entering the cerebrum, divides into a well-defined radix mesalis and radix lateralis.

Prosencephalon.-The mantle portion of the cerebrum is represented, as usual among fishes, only by a delicate transparent membrane, the pallium, lined with epithelium. This pallium is entirely free from the basal portion of the cerebrum on the dorsal and lateral aspects, and below it is frec as far mesad as the lateral edge of the radix lateralis of the olfactory, i.e., the sinus rhinalis. The median fissure is not prominent, being represented dorsally by a slight fold of the pallium in the median line. Caudad the pallium is plicated in this region to form a considerable choroid plexus. Cephalad the median fissure is deepened until at the exit of the olfactory crura a similar fold is thrust up from below and the two crura are entirely separated. The pallium, however, continues to envelop the crura, maintaining about the same relations as in the cerebrum, i.e., attached only ventrally, free at the sides and above. Thus the lateral ventricles are continued cephalad into the rhinencephalon, as described above. For a discussion of the cerebral ventricles see beyond. 
The basal portion of the cerebrum consists of two lobes which are considered to be the homologues of the axial lobes of the Sauropsida. They are connected below by a membrane which may be considered as a continuation of the pallium, and are otherwise quite distinct from each other except in the region of the anterior commissure. Each lobe is oblong, about as high as it is wide, and about one-fourth longer than it is wide and is attached to the diencephalon by by its caudo-ventral angle. The dorsal (ventricular) surface of these lobes is marked with an intricate system of fissures and convolutions, which, however, seem not to be very constant, even in the same species. There are four fissures which are almost always obvious externally, though somewhat variable in size and position. They are found in other fishes quite generally and are here named in accordance with the nomenclature of Prof. C. I. Herrick as given elsewhere in this number. The most strongly-marked and constant fissure is the rhinalic fissure, or sinus rhinalis, on the ventral surface. This marks the line of union between the pallium and the basal lobe. This line passes from the lateral edge of the olfactory crus at its point of exit caudo-laterad to about the centre of the hemisphere; it then turns at an obtuse angle, passing caudo-mesad to the lateral edge of the optic nerve at its exit. The two rhinalic fissures thus define a broad pentagonal depression in which lies the decussation of the optic nerves, and dorsad of which, in the substance of the basal lobes, lic the olfactory crura, and farther caudad, the fibres of the crura cerebri. It is present in other teleostean brains, though not usually as strongly marked as in the Siluridæ, and may be called the rhinalic aspect. On the dursal surface the most prominent fissure is the frontal fissure, which arises on the fronto-median aspect of the cerebrum from about the middle of the olfactory crus at its exit and passes cnudo-laterad in an irregular line almost to the diagonally opposite angle of the basal lobe. Here it meets the occipital fissure, which arises on the latero-caudal aspect 
and passes caudo-mesad. By these two fissures there are defined a large mesaxial lobe mesad of the frontal fissure and a narrow occipital lobe caudad of the occipital fissure. The fourth important fissure is the Sylvian, which is not so strongly developed as the preceding. It arises on the ventral surface in the centre of the lateral aspect and passes dorsad. This fissure, with the occipital, defines a triangular lobe, with the apex directed ventrad, the cuneate lobe. Behind the cuneate and ventrad of the occipital lobe, from which it is separated by a small fissure, is a large lobe which may be called the temporal lobe, though in the cat fish it occupies the caudo-ventral end of the cerebrum. The term hippocampal lobe is applied to the lip, or ventral extrusion, just laterad of the sinus rhinalis. Cephalad there is another small fissure which may be considered as a part of the rhinalis. It arises from the lateral edge of the radix lateralis, passes dorsad and, with the frontal fissure, circumscribes a frontal lobe. This lobe lies immediately dorsad of the olfactory crus and is very small. There is still another noteworthy fissure in the median sinus between the two basal lobes. It runs in each lobe longitudinally in both directions from the anterior commissure, It is best observed in transection. There are are other small fissures on the dorsal surface, but they seem not to be constant and are considered unimportant. It is to be remembered that all of these fissures, except the rhinalis and possibly the Sylvian, are spurious fissures and are not to be homologized with the cerebral fissures of higher animals. That is, they are fissures of the axial lobe, not of the cortex, for this dorsal surface is a ventricular surface and is clothed with epithelium, like the pallium. The epithelium here, however, tends to be more columnar than that of the pallium.

To understand the full significance of these lohes it will be necessary to examine the cellular histology of the cerebrum in some detail. A transection cephalad to the anterior commissure reveals three areas sharply differentiated histo- 
logically. The mesaxial lobe is characterized by small flaskcells, with large granular nuclei and dense nucleoli. They are very closely packed, with a strong tendency toward a zonary arrangement. The lateral lobe is characterized by similar elements more sparingly distributed, but still showing an evident zonary arrangement. This latter is particularly true ventrally. Dorsally the cells are less numerous, and those of the type found in the central lobe predominate. The central lobe lies between the two last mentioned and typically does not appear on the dorsal surface, being triangular with the apex directed dorsad. The cat fishes, however, present a marked exception to the latter point. The histological elements are large cells lying in a clear stroma. They are spindle-shaped or multiangular, all with very large processes, large circulr nuclei and dense nucleoli. The central lobe is nowhere sharply separated from the lateral lobe. On the other hand, the frontal fissure separates it very clearly from the mesaxial lobe, especially peripherally. The structure of the occipital lobe closely resembles that of the central, while the temporal lobe has the small cells of the mesaxial, somewhat less abundant, but with the same zonary arrangement.

The prosencephalon, as a whole, is considerably larger than the optic lobes, but very much smaller than the cerebellum. It attains to about the average size as compared with other Teleostei thus far examined.

Diencephalon. - The thalamus in the adult cat fish is entirely hidden from the dorsal aspect by the optic lobes and the cerebellum. Even the attachment of the epiphysis is obscured by the forward extension of the cerebellum. The epiphysis is very much as in some Lacertilia. It arises as a small membranous tube lined with epithelium immediately cephalad of the superior commissure, passes dorsad enwrapped by the plexus which fills this region, then turns abruptly cephalad passing under the ccrebellum and over the cerebrum. It lies in the shallow median fissure in intimate 
contact with the pallium as lar cephalad as the exit of the olfactory crura, then turns dorsad to the roof of the cranial cavity. The diameter of the tube is about. I $\mathrm{mm}$. at the basc, but increases slightly as it passes out. About the base of the epiphysis the membranous roof of the third ventricle is intlated dorsad to form a small closed sac which is nearly spherical and about $\mathrm{I} \mathrm{mm}$. in diameter. This represents the dorsal sac, which is so conspicuous a feature in many fish brains. In this case it is entirely obscured from view in the brain beforc dissection by the over-arching cerebellum. The walls of this sac are intricately plicated, the folds cmbracing the base of the epiphysis and forming what has been previously mentioned as the homologuc of the choroid plexus. The epiphysis is related to the roof of the cerebral ventricles cephalad in essentially the same way; i.c., it is imbedded in the pallium and surrounded by it. Thus morphologically the dorsal sac is produced forward nearly to the end of the cerebrum, though its cavity has been all but obliterated.

On the ventral aspect the hypoaria and hypophysis cover nearly the entire cephalic portion of the brain. Each hypoarium is a pear-shaped body, flattened dorso-ventrally, with the smaller end directed cephalad and the more concave surface mesad. At the cephalic end of each hypoarium is a small tubercle lying immediately ventrad to the lateral portion of the optic nerve at its exit from the brain. In the adult the hypoaria are divaricated cephalad by the cinereum. This body is cordate with the apex directed caudad, and is somewhat over half as long as the hypoaria. Attached to its apex and lying in the narrow cleft between the caudal ends of the hypoaria is the saccus vasculosus, which, in large brains, sometimes attains a diameter of $3 \mathrm{~mm}$. This is a membranous sac, the base of which, lying between the hypoaria, is filled with a vascular plexus, resembling in structure the vascular portion of the epiphysis of higher animals. The more expanded portion, overlying the larger ends of the hypoaria, is discoid or sub-spherical, more delicate 
in texture and dilated with fluid. Immediately caudad of the saccus vasculosus a large blood-vessel enters the brain in the median line. This is always present and seems to represent the area perforata posterior of higher brains. The broader end of the cinereum is directed cephalad and is indented in the median line by a deep sinus extending to its centre. This point is the most ventral projection of the cinereum, and from it the infundibulum passes out into the hypophysis. This appendage is slightly ovoid, with the larger end directed cephalad, $4.5 \mathrm{~mm}$. long by $3.5 \mathrm{~mm}$. wide and high. The stipe is filiform, slightly thicker at the base and attached to the body of the hypophysis at a point about one-fourth of the distance from the caudal end of the latter. The hypophysis is solid, and of a uniform texture.

Mesencephalon.-The portion of each optic lobe which is exposed is ovoid, with the larger end directed cephalad and the long axis passing obliquely dorso-caudad. The two lobes are widely divaricated by the cerebellum. The roof of the mesencephalon is depressed, thin, and devoid of cellular elements, except internally in the tori longitudinales ("fornix" of authors) adjacent to the ventricle. The mesencephalon does not reach the ventral surface of the brain at any point. In this region, cephalad, that surface is entirely occupied by the hypoaria, while the portion caudad of the hypoaria is to be considered a forward extension of the medulla, as in higher animals.

Epencephalon.-In this group of fishes the cerebellum is the most characteristic feature. It consists of two major divisions, one external and one internal. Both are well developed, the former to an unusual degree. The whole mass of the first division is folded upon itself at an angle of $90^{\circ}$, thrust cephalad, and closely appressed to the subjacent optic lobes and hemispheres. The entire extent of the fourth ventricle is thus exposed, in striking contrast to the brains of most other fishes. As viewcd from above, the cerebellum is nearly rectangular, with a lateral expansion caudad, and it 
extends forward far enough to cover a quarter of the cerebrum. This portion is oval in transection with the longer axis horizontal. Caudad, at the point of union with the medulla, it expands to a width greater than that of the brain at any other point. The two lateral lobes thus produced contain white matter, chiefly in the form of fibres, passing caudad into the medulla, and are to be considered as portions of that body, homologous in part with the restiform bodies. They lie farther caudad than the cerebellum proper, one on each side of the fourth ventricle over about the middle of the medulla. A small transverse fissure is present on the dorsal surface of the cerebellum, a few millimetres cephalad of the fourth ventricle. Between this fissure and the fourth ventricle are transverse fibres passing apparently from one lateral lobe to that on the opposite side. Cephalad of this fissure the grey and white matter are arranged in the usual manner, the grey filling the centre and enveloped by the white. White fibres enter the cerebellum from below in the centre of the grey matter and thus form a sort of arbor vite, as in higher animals. In the median line, about $1 \mathrm{~mm}$. cephalad of the to the caudal end of the ccrebellum, a very narrow ventricle arises from the aqueduct of Sylvius and passes dorsad in to the cerebellum for about two-thirds of the way to its dorsal surface. With this exception the cerebellum is solid.

The internal division, or volvula, lies in the aqueduct of Sylvius immediately cephalad of the small ventricle of the cerebellum. It presents the appearance of having been formed by folding back upon itself through an angle of $90^{\circ}$, not the entire cerebellum, as before, but merely the half which lies cephalad to the cerebellar ventricle. It is as if that half had projected much farther ventrad than the other half, as a free lip, and had then been bent cephalad into a horizontal position. Thus the grey matter which normally lies next the cerebellar ventricle becomes ventral adjacent to the aqueduct of Sylvius, and the white matter becomes dorsal adjacent to the roof of the optic lobes. This volvula is about 
half as long as the exposed part of the cerebellum, and is thrust cephalad into the third ventricle nearly to the superior commissure.

Metencephalon.- The medulla is remarkable for its great depth, as well as its great width. The width is duc, in large measure, to the presence of the wide, lateral lobes connected with the descending tracts of the cerebellum. The depth is, in part, due to the great development of the two pairs of dorsal tuberosities. Of these the cephalic or trigeminal tubers are much the larger. They rise in the floor of the fourth ventricle to a height nearly as great as that of the cerebellum. They are strictly intra-ventricular, and are covered by the membranous roof of the ventricle. The interior is occupied by fibres and cells pertaining chiefly to the trigeminal nerves. The other pair of prominences, the vagal tubers, are, for the most part, extra-ventricular. The fourth ventricle lies between them, and its membranous roof extends from the mesal surface of the one to that of the other. Most of the fibres of the dorsal root of the vagus take their origin from this pair of tuberosities. Behind the vagal tuberosities the fourth ventricle closes. Its caudal limit is marked by an elevated ridge, or crest, of transverse fibres. Farther caudad, at the exit of the so called first spinal nerve, the medulla is thickened on both dorsal and ventral surfaces, behind which it passes at once into the spinal cord. On the ventral surface there is another considerable thickening at the exit of the trigeminus. The ventral surface otherwise presents very few features of note. The ventral fissure, too, is not so deep as the dorsal. The cranial nerves are discussed elsewhere in this article.

Ventricles.-In discussing the encephalic ventricles we shall pass from the spinal cord cephalad. The canalis spinalis is very small. It gradually enlarges in the medulla up to the exit of the dorsal root of the vagus, where it is suddenly extended dorsad to the surface, thus forming the fourth ventricle. From this point the ventricle is very deep, but 
quite narrow until the vagal tubers are passed, after which it rapidly expands until at the exit of the ventral root of the vagus it occupies the whole dorsal surface, not excepting the lateral, lobes or cerebellar peduncles. Farther forward the ventricle contracts into the aqueduct of Sylvius and passes under the cerebellum, into which it sends a very narrow arm. This cerebellar ventricle passes directly dorsad and does not turn cephalad with the cerebellum. Immediately cephalad of the volvula the aqueduct expands into the third ventricle, which, at the same time, communicates laterally, by wide openings, with the ventricles of the optic lobes near their cephalic ends. The latter bodies are hollow throughout their entire length, though the ventricle is much larger cephalad. In this region the triangular ventral part of the third ventricle is bridged over by the superior commissure, and from this point forward severs its connection with the dorsal part. The torus longitudinalis (fornix) very soon comes in to contact with the superior commissure, and thus separates the ventricles of the two optic lobes again near their cephalic ends. Beneath the superior commissure the third ventricle dips suddenly ventrad in the form of a narrow cleft, reaching to the surface. In its descent it sends two branches laterad into the hypoaria, expands in the cinereum, and then sends an arm caudad into the saccus vasculosus and another cephalad into the infundibulum. The ventricle of the cincreum lies in about the centre of that body. It is about one-third as wide as the cinereum, but very thin dorso-ventrally. Ventrad of this expansion the third ventricle gives off a very small branch on each side $(.5 \mathrm{~mm}$. in diameter $)$ which is lined with very strong epithelium and extends caudad near the median line between the hypoaria for some distance into the base of the saccus vasculosus. The ventricles of the hypoaria are crescent-shaped, diminishing caudad to sub-triangular and oval. Just cephalad of the superior commissure the epiphysis arises from the dorsal surface, as above described. Cephalad of the dorsal sac the third ventricle passes into the cerebral 
ventricles by a wide foramen of Monro. Aula and portæe can scarcely be separately distinguished. The median fissure is so poorly developed that the lateral ventricles of the two hemispheres are practically continuous for the whole length of the cerebrum. The limits of the cerebral ventricles are implied in the description of the pallium given above. They pass from the median fissure laterad to the sinus rhinalis of each side and envelop the entire cephalic aspect of the basal lobes. The basal lobes are entirely separated, except in the region of the anterior commissure, by the cerebral ventricle, down, even to the extreme ventral limit of the cerebrum, where the ventricle is bounded by a membranous floor. The relations of the cerebral ventricles to the ventricles of the olfactory lobes are discussed in the section devoted to the rhinencephalon.

\section{IDESCRIPTION OF PLATE XVII.}

Fig. I. Dorsal view of the brain of the adult mud cat fish, or yellow cat, lilodicts olitaris Gill and Jordon. The olfactory lobes, with most of the crura, have been removed. The trigeminal, vagus and first spinal nerve-roots are shown. $\times 2$.

Figr. .). Dorsal view of the brain of a young bull-pout, Amiurus catus (iill, three inches long. The olfactory lobes have been removed. $\times 4$.

fig... Dorsal view of the brain of a much younger bull-pout, one inch long. The olfactory crura are reduced until the olfactory lobes are closely appressed to the hemispheres. $X$, 1 .

Figr. 4. Ventral view of the brain of the adult mud cat, Pilodictis oliveris. The olfactory lobes, hypophysis and saccus vasculosus have been removed. The Roman numerals refer to cranial nerves. $\times 2$.

Fis..j. Lateral view of the brain of Pilodictis oliz'aris, designed to illustrate the distribution of the cranial nerves. The various nerveroots are retained, as nearly as may be, in their natural positions. The olfactory lobes have been removed; ol., olfactory crus; "of., optic. nerve; $V_{1}, V_{2}, V_{3}, V_{1}, V_{3}, V_{6}, V_{7}$, the seven principal branches of the trigeminus nerve; $F_{1}, F_{2}, F_{3}, F_{4}$, the four principal foramina of the trigeminus verve; $1 \%$, the facial nerve; $\boldsymbol{k}$. dep. of., nerve of the depressor operculi; $"$ le $z$. "p., nerve of the levator operculi; VI/l, acoustis: nerve; $/ X$, glosso-pharyngeal nerve: $s X$, ganglion of the vagus nerve; $1 . l l$., nerve of the lateral line; $x^{*} i s i$, , visceral branch of the vagus; $X$ th., thoracic branch of the vagus; $n . d . p$. nerve of the depressor of the pectoral tin; $n . l . p$. , nerve of the levator of the pectoral 
fin: $I, I I, I I I, I V$, nerves to the four gills, respectively; $n . s p$., the first spinal nerves.

For full discussion of these nerves see text under cranial nerves.

Fig. i. Transection of cerebrum of Irtalurus cephalad of the anterior commissure.

Fig. $\%$. Transection of the same brain at the level of the pracommissura, Prec. The tracts from the olfactory radices are seen in section dorsad of the pracommissura on either side the median line. $O . t r .$, optic tracts; I'cd., peduncular fibres.

Fig. \&. Transection of the same brain at the level of the habena, $H$. ; Cer., cerebellum.

\section{II.-STUDIES ON THE BRAINS OF SOME AMERICAN FRESH-WATER FISHES.}

\section{I. HERRICK.}

\section{A.-TopograpHy.}

The olfactory lobes have an essentially similar structure throughout the various families of Teleosts, but there is a great variation in position, which is a function of the position of the nasal capsules and the form of the cranial cavity.

Every gradation between an olfactory lobe closely soldered to the cerebrum and one separated by many times, the length of the whole brain from the hemispheres may be enencountered in our fresh-water fishes. The gizzard-shad (Dorosoma), which has a decidedly reptilian brain, is an illustration of the first type (Figs. $6-7$, Plate XIX). Sections of the olfactories of this species in front of the cerebrum are semi-oval, with the larger extremity of the oval dorsad. A shallow groove occupies the middle of the dorsal surface. In section, the membranes may tend to separate from the lobe, but there is no true ventricle. At this level the lobe is composed of the usual glomerulary structure with Deiter's nuclei, and the whole is richly supplied with small vessels. 
The glomerules are chiefly massed cctad. The nervous element are small and inconspicuous.

The cerebrum overlaps the olfactory dorsally, and the lateral ventricle descends to the level of the olfactory mesally, but is separated from the crus by a small spur of the cerebrum. Gradually the olfactory lobe narrows into the crus, and is embraced by the cerebrum latcrad as well as mesad. The cerebrum is completely cnveloped by the pallium and ventricle except near the attachment of the crus and thence some distance laterad to beyond the rhinalis fissure or sinus of the ventral surface. There is a dense collection of fusiform cells mesad of the crus on either side of the ventricle. The latter represents a forward protrusion of the third ventricle rather than the aula. The centre of the crus is occupied by a tract, while others gather about the rhinalis sinus. The first mentioned tract can be easily traced as far caudad as to the anterior (or interlobular) commissure, where it turns mesald, decussates with its fellow and continues in nearly the same relative position toward the thalamus upon the opposite side. Other fibres derived from the crus follow the rhinalis sinus and constitute a distinct radix lateralis which can be traced to a point opposite to the commissure, where they seem to enter the hippocampal lobe, to be described beyond, although part may pass directly mesad to the commissure.

In Hyodon (the moon-eye) the olfactory lobes are un. usually large and lie some distance from the cerebrum, while the lateral ventricles extend well out upon the dorsal surface of the crura cephalad of the cerebrum. The crura are accordingly flattened, and enter the meso-cephalic angle of the cerebral lobes in two partially distinct radices. The radix lateralis is smaller, and spreads out about the sinus rhinalis in the form of a series of small bundles. The radix mesalis is a large bundle, which retains its position in the ventro. mesal angle of the cerebrum as far caudad as the anterior commissure. 
The buffalo fish (Carpiodes) furnishes an illustration of long-stalked olfactories. The crura are enormously clongate and the ventricles extend a long distance upon the dorsal surface of the crura proper, being covered by a thin pallium similar to that of the hemispheres.

The arrangement is well seen in Fig. 1, l'late XIX, where the dorsal pallium has been removed from the cerebrum but remains on the crura. The sections (Figs. $4-5$, Plate XXI) illustrate substantially the same arrangement as seen in the black-horse (Cycleptus). The radix lateralis is wider than its fellow and very thin vertically, while the radix mesalis is rather compact and enters the ventro-mesal angle of the cerebral hemispheres.

The radix lateralis first becomes attached to the cerebrum by its lateral border. Then the mesal radix becomes attached to the mesaxial lobe, which is here quite distinct, thus cutting off a spur of the ventricle, which remains distinct some distance caudad. The connection with the common ventricle or aula is upon the cephalic aspect, affording evidence that the porta: in this case may almost be said to lie entirely cephalad of the hemispheres. The forward extension of the ventricles beyond the cerebrum is, we believe, a fact of primary importance in understanding the morphological significance of fish brains. The subsequent course of the two radices are distinct, and corresponds to that described in the black-horse ( $C y$ cleptus), which furnishes one of the best illustrations of the tubular olfactory crus. Transverse sections show that the arrangement of ventricles, ctc, is the same as that described by my brother in the cat-fish. The transection of the crus cephalad of the cerebrum shows it to be composed of a tubular sheath of membrane, with the fibres collected in two somewhat distinct bundles along the ventral surface, entering the radix lateralis and mesalis respectively. There is, however, a narrow band of fibres between the sheath and the epithelium lining the ventricle. The ventricle passes into that of the cerebrum at a point where the 
latter entirely surrounds the frontal projection of the hemispheres. The pallium thus embraces both the olfactory and cerebrum before the olfactory enters the hemisphere (see Plate $\mathrm{XX}$, Figs. $1-4$ ).

In Siluroid fiishes the olfactory lobes are stalked in the adult. The two radices are scarcely distinct before entrance into the cerebrum, but at once separate thereafter. According to $\mathrm{C}$. Judson Ferrick, the ventricles enwrap the crura nearly completely throughout their course (see ahove for details.)

In the eel the olfactory lobes are relatively large and sessile (Plate XIX, Figs. 9-II), and are overlapped by the hemispheres, which are lunulate in section. The mesaxial lobe is distinct but large, and receives the radix mesalis on the ventro-mesal angle. The two radices appear before the crus enters the hemisphere.

In the eel, more easily than in any other tish cxamined, the course of the radix mesalis can be clearly traced. The tract prescrves its identity fully, and crosses as an entirely distinct bundle of the hippocampal element of the anterior commissurc. After decussating it reappears in the corresponding position on the opposite side, and can be traced to the medi-dorsal part of the thalamus. The radix lateralis follows cephalad to the region of the anterior commissure, where it turns suddenly mesad and crosses through the peduncular bundles and unites with the tract of the radix mesalis and decussates with the latter. The fibres of both of these radices are light-colored, while the bulk of the anterior commissure fibres are very dark. Horizontal sections especially leave no doubt as to the course pursued by these fibres, though, of course, the possibility is not excluded that other connections exist, especially with the cell masses corresponding to the hippocampus.

In the buffalo fish (Carpiodes) longitudinal sections seem to show that part, at least, of the fibres of the radix lateralis pass to the hippocampel lobe. 


\section{SUMMARY OF OIFACTORY I.OBES.}

1. The olfactory lobes are exceedingly variable in size and position, but exhibit no decided differences in structure.

2. The primary conclition is similar to the permanent condition in Sauropsida, i.e, the lobes are sessile or attached by short crura to the base of the cerebrum; but their connection with the cerebrum is more accidential than essential.

3. Whether they become stalked or not depends on whether the growth of the head removes the peripheral organs of smell from the brain at an carly period, and whether, in case it is so removed, the olfactory nerve or crus is elongated. The probable determinant for the latter is the relative rate of development of the various regions of the head. The olfactories arc always sessile in an early stage.

4. The crura contain two distinct tracts, forming a radix mesalis and lateralis.

5. The lateral ventricle is frequently extended into the the crura, but the form it assumes varies. In the extreme case the crus is a hollow cylinder, with the fibres chiefly collected in the ventral portion. In other cases the ventricle simply extends a short distance along the dorsal surface of the crus.

6. In some cases there is a rudimentary olfactory ventricle in the substance of the lobe.

7. The radix mesalis enters a special mesaxial lobe of the cerebrum and its fibres decussate in the commissura interloborum, forming with the next a hippocampal commissure and fornix.

$\mathrm{S}$. The radix lateralis follows a gentle groove (sinus rhinalis) on the ventral surface of the hemispheres to a point opposite the decussation of the radix mesalis when it turns abruptly mesad and crosses to the opposite side; but probably also gives oft fibres to the hippocampus. According to Owen the olfactory lobes are sessile in I'erca, Scomber, Esox, Pleuronectes, Blennius, Anguilla, Gasterosteus, Eper- 
lanus, Cottus, Trigla, Amblyopsis, Echeneis, the Ganoidei and Lepidosiren; and long-stalked in Salmo, Cyprinus, Brama, Tinca, (iadus, Lota, Hippoglossus, Clupea, Belone, Leucioperca, Cobitis, Plectognathi and Plagiostomi.

The Corobum.-The topography of the cerebrum cannot be satisfactorily discussed until much extencled and careful observations have been accumulated. In the groups examined it is relatively constant, and such diflerences as appear are often less important than they at first seem. The form varies chiefly as a result of the varying size and position of adjacent portions of the brain. The dorsal view usually presents a sub-quadrangular outline, tending to oval. From the side one may observe a rudimentary fissure and curvature corresponding to the fissure of Sylvius of higher brains. The transverse section is nearly always sub-triangular, with the curved base of the triangle dorsad. 'Ihe cerebrum presents three well-marked aspects: a mesal surface, facing the median fissure (in cases where the pallium of the two hemispheres fuses compleiely this aspect is absent or represented solely by the corresponding aspect of the axial lobe); a dorso-lateral aspect, gencrally one continuous curved surface; and, third, a ventral or rhinalic aspect. The last mentioned surface differs from the others in being chiefly a non-cortical or axial surface, as is the case in the corresponding area of higher brains. It is bounded laterally by a more or less distinct fissure or sinus, the rhinalis sinus, which is more distinct, cephalad. This fissure is the undoubted homologue of the rhinalis fissure of higher vertebrates in so much as the radix lateralis of the olfactory crus occupies the adjacent region. The pallium separates at this point. It must be constantly kept in mind that the fissures upon the dorsal surface of the cerebrum of fishes cannot have the same significance as the cortical fissures of mammals. The Sylvian fissure, however, seems to be obscurely indicated by a depression near the midfle of the lateral surface, which results from an incipient flexture. There are upon the dorsal surface a number of de- 
pressions, which are impressed upon the axial lobe, and may or may not be obvious before the removal of the pallium. Three of these are especially constant. First, the frontal fissure, separating the mesaxial lobe superficially from the remainder of the cerebrum. This fissure begins upon the cephalic or ventral surface and extends parallel to the longitudinal fissure a longer or shorter distance upon the dorsal surface. The occipital fissure occupies an analogous position upon the occipital region, and in extreme cases unites with the frontal to form an occipito-frontal groove. The third fissure is the dorsal portion of the Sylvian fissure, and extends a variable distance toward the occipito-frontal.

By the aid of these external landmarks and the variations in internal structure, a few pretty well-marked regions of the axial lobe may be conveniently designated. The mesaxial lobe is that region bordering the longitudinal fissure and limited laterally by the frontal fissure. The central lobe is an ill-defined region, with few large spindle cells lying in the central and ventral portions of the cerebrum. In some cases there is a well-defined line of demarkation between this and adjoining areas. It is in the ventral portion of this lobe that the peduncles enter the cerebrum, and it may be looked upon as forming in a special sense the homologue of the striatum. The latcral or parictal lobe embraces the lateral portions of the cerebrum, and, though frequently imperfectly defined externally, differs in cellular structure sufficiently to make its recognition possible. A small lobule lying between the Sylvian and occipital fissures may be called the cuneus without implying any homologies with higher brains (see Fig. I, Plate XIX). An occipita! lobe may be recognized in the caudad projection lying adjacent to the habence, and a $t \mathrm{~cm}$ poral lobe upon the caudo-lateral aspects behind the Sylvian fissure. There is a caudo-ventral projection which is invariably present, and, from its being the starting-point of the posterior part of the pallium, may be compared to a hippocampus, and will be referred to as the hippocampal lobule. 
The Thalamus.-In general, it may be admitted that Baer correctly characterized this region in the statement, "Fs sicht so aus, als ob das Mittelhirn das $Z$ wischenhirn unterdrückt habe." The strong optic nerves and tracts serve to constrict the organ greatly and obscure the original form. In some cases the origin of the epiphysis and habena are visible from above, while in others, like the black-horse, the mesencephalon is thrust forward by the great development of the volvula, so as to cover much of the cerebrum itself. Apparently, as a result of the constriction of the middle of the thalamus, it is forced caudad, and, to supply the requisite nervous material, develops the hypoaria or inferior lobes, which, instead of representing the mammillary bodies, seem to contain the homologues of the displaced walls of the median part of the thalamus. The saccus vasculosus marks the caudad extension of the thalamus. It seems necessary to recognize three parts of the thalamus, as follows. The prathalamus: This includes the ventral median region caudad of the anterior commissure and ventrad of the hippocampal lobules. It is quite distinct from the adjacent parts of the cerebrum, and contains the various tracts passing from it toward the lower parts of the brain. The mid-thala. mus is that part which corresponds to the principal part of the organ in reptiles and bears the habena. Its caudal limit may be recognized in the inferior commissure. Caudad of the this, and extending as far as the saccus vasculosus, is a portion which is covered dorsad by the optic lobes, and bears laterally the hypoaria. This may he termed the post. thalamus.

There is no difficulty in recognizing these divisions in any of the Teleosts examined.

Mesencephalon.-The topography of the optic lobes differs from that of reptiles only by reason of the greater or less invasion of the optic ventricle by the volvula. Transections of the mesencephalon of the eel cephalad resemble corresponding sections of the turtle closely. There is a slight pro- 
jection into the ventricle from the base, forming the colliculus or torus, with the concentric arrangement of cells characteristic of the colliculi, and the rather thick tectum cxhibits the the same pronounced stratification of elements. Along the median dorsal line the dependent ridges known as the tori longitudinalis are evident, though relatively small, and scem to make up for the slight development of the granular zone of the tectum.

In the drum the extensive development of the volvula, and its compact plication within the ventricle serve to greatly modify the tectum and other bodies. The whole organ is tilted forward so that the apparent cephalic aspect really represents a large part of the dorsal. The tori are therefore cut longitudinally in transections cephalad, so that their apparent size is increased. (On the dorsal surface, however, the tectum is forced apart, and the tori form the starting points for the membranous expansion which bridges over the interval separating the two halves. The colliculi are likewise thrust apart and modified as to form by the same means.

The black-horse affords an illustration of an extreme modification resulting from the exceptional development of the volvula. The mesencephalon in this case extends far cephalad over the hemispheres, while its entire dorsal surface is reduced to a membrane. The tori are thus extended in the same plane as the tectum, and serve as supports for the membranous roofs (Plate XIX, Fig. 4). The position and structure of the corpus posterior will be discussed in the histological part of this paper, as will the cranial nerves.

The Cerebellum.-The present notes may be regarded as supplementary to the earlier paper on the archetectonic of the cerebellum. In it we attempted to show that the variations in structure exhibited in different groups could all be reduced to a common type and their diflcrences explained by tracing the invaginations and evaginations of the walls of the fourth ventricle. No better illustration of this principle 
could be selected than that furnished by the Teleosts. The cerebellum is the most variable, and, at the same time, the most characteristic segment of the brain. It varies greatly even in the same group, yct the plan of structure is constant and is even suited to characterize families and genera. The structural peculiarity which is characteristic of all fishes is the volvula (valvula of authors). This organ may be briefly defined as a modification of that part of the roof of the aqueduct of Sylvius which lies between the valve and the tectum. Its structure is essentially that of the cerebellum, and it is directly connected with the tectum cephalad. The extent to which it develops seems to depend upon a variety of circumstances. When for any reason the cerebellum fails to acquire the normal size the volvula may compensate therefor. The size of the cerebellum as a whole (including volvula) is undoubtedly a function of the activity of the fish. Thus, for example, the black-horse and buffalo-fish are allied systematically and live in the same streams, but the former is a very active carp, while the latter is sluggish and massive. The main portion of the cerebellum is of relatively the same size in the two fishes, but a glance at Plate XIX, Figs. I and 4, will convince one that the development of the volvula in the black-horse corresponds to its active habits. In the typical cases the volvula is but a forward fold into the optic ventricle, but numerous secondary modifications obscure this primitive simplicity. It may be well to refer to several illustrations at this point, remembering that the cerebellum is mechanically the least stable of the structures of the brain. The axial portion of the organ is a thickening of the roof of the fourth ventricle. The caudal and lateral aspects of the roof are reduced to a membranous velum or infolded to form a plexus, while the cephalic boundary is altered to form the velum anterior or volvula. Thus the only rigid attachment of the cerebellum is that formed from the relatively small pedun. culi. Rotations in all directions except cephalad meet with no opposition, and the absence of closed cranial walls permits 
the resulting organ to occupy almost any portion with reference to the axis of the brain.

The moon-eye, Hyodon, is perhaps the most reptilian brain of the osseous fishes here noticed, and has the simplest cerebellum. It is probably one of the best types in which to study the archetectonic of the cerebellum and optic lobes in comparison with those of reptiles. The optic lobes are large and almost absolutely unmodified by the cerebellum, except in so far as the corpora posteriores are thrust ventrad and laterad. The volvula is well developed, and its dorsal lamina passes directly into the tectum. The valve is small. Immediately caudad of the valve the cerebcllum swells into a large, thick sac which soon becomes free from the walls of the medulla. The cavity of the cerebellar ventricle is not suppressed, and there is very little to suggest the complicated projections of the calamus and vagus regions of the medulla found in most fishes, especially the carps. The cerebellum thus forms a simple lobe, projecting over the partly exposed opening of the fourth ventricle. It is relatively small, as may be gathered by a comparison with corresponding views of the Gizzard-shad (Plate XIX, Fig. 7).

As in Lepidosteus, the cephalic part of the mesencephalic ventricle is not entered by the volvula. Transections in front of the oculomotor roots resemble similar sections of reptilian brains, except for the presence of the small hypoaria. The tori longitudinalis, or appendages of the median line of the tectum, are large.

The volvula extends cephalad to just in front of the third nerve-ruots where it appears two-lobed, having the apparently ectal (ventricular) surface composed of gray matter, a median zone of Purkinje's cells, and a central mass of white matter. Farther caudad the cavity due to the invagination is encountered, surrounded by the white zone, which is, therefore, morphologically ectal. The dorsal wall of the sac thins out and passes into the membranous caudal wall of the optic lobes, which are obviously paired at this level. 
The fourth nerves pass caudad to the optic lobes, around which they arch, and enter the narrow, slit-like opening of the volvula and then continue cephalad nearly to the level of the caudal margin of the hypoaria, where they meet and dip suddenly ventrad into the substance of the valve, then, after decussating, they continue cephalad to the ventrolateral margin of the valve, and, arching about the aqueduct, enter the nidulus near the median line and adjacent to the aqueduct and bounded ventrad by the dorso-median fasciculus.

Caudad of the valve the roof of the fourth ventricle expands and thickens in to the median lobe or vermiforme of the cerebellum, being for sometime connected with the lateral walls of the ventricle by thick lateral lobes which have not the structure of the cerebellum, but contain an intimate mixture of granules, nerve cells and fibres. The cerebellum proper is, as above said, simply a caudad pouch from the roof of the fourth ventricle, which, however, remains for some distance in contact with a mass similar in composition to the lateral lobes which forms the transition into the velum posterior, and is homologous with the "bursa" of the sturgeons.

In the gizzard-shad, although the brain is so similar to the moon-eye, externally, the cerebellum is remarkably modified in details of structure. What at first gives great trouble, is the fact that in the axial part of the cerebellum or vermiform lobe the gray matter is apparently ectad instead of internal.

To a point about one-third the length of the optic lobes from their caudal boundary the relations are as above. The volvula is small, and its cavity nearly closed. The cerebellum proper is driven forward between the optic lobes, and especially dorsad, so that, as though by actual lateral pressure, the organ is thrust together upon itself and its dorsal and cephalic surfaces are folded in along the median line and the lateral white matter is reduced to a mere membrane, only recognized by careful examination. The appearance of lateral compression in the fungiform contours 
2yo Journat oh Comparative Nimbolomy.

is remarkably verified in transverse section. A caudad diverticle of the cul-de-sac from the exterior extends to the level of the valve where the fourth nerve enters without the curvature described in the moon-eye, but which is here unnecessary by reason of the divarication of the optic lobes. At this level the cerebellum is obviously folded upon a longitudinal fissure for almost its whole height, though the fissure has been practically obliterated by the union of the walls. A little caudad a rudiment of the caudal diverticle of the fourth ventricle can be detected, and the arrangement of the gray and white matter shows that the duplication has been affected in the usual manner, yet the cavity is absent, and the whole organ is so closely adherent to the combined lateral lobes that only a comparison with simpler types explains the seeming anomalies.

This case is very instructive as showing how far the distortion and secondary union of parts may obscure perfectly simple homologies.

In the eel the cerebellum may be characterized as a simple depressed variety with small volvula. In striking contrast to the gizzard shad, the modifications are such as could most easily be referred to the effects of pressure from above. The volvula is exceptionally small. The fourth nerve enters directly behind the optic lobes, decussating in a very obvious and uncomplicated valve. The dorsal lamina of the volvula passes into the tectum opticum with but a short velum cerebelli anterior. Caudad of the trochlearis there is a slight pocket and corresponding revolution cephalad. Then for some distance the cerebellum is a simple thickened dorsal wall of the fourth ventricle which, nevertheless, has the appearance of having been thrust ventrally into that cavity, with the result of thrusting the ventricular gray layer of the cerebellum laterad and dorsad, so that it is thicker on the lateral than the ventral aspects and projects on either side as a slight protuberance on the lateral margin of the dorsal surface. The caudad portion of the cerebellum is a sac-like 
diverticle, the lumen of which has been extinguished by the same ventrad pressure, so that the dorsal and ventral granular layers adhere and fuse in the centre. Some evidence of the cavity still remains, however, in spurious lateral recesses, consisting only of membrane connccting the partially everted lateral portions of this ventricular layer. The posterior portion of the cerebellum is thus reduced to a double leaf-like valve over the calamus region.

In Cyprinoid fishes the cerebellum is greatly developed, but strictly the same principle is followed as indicated above. The volvula is highly developed and complicated. The connection between the dorsal lamina of the volvula and the caudo-lateral edges of the optic tectum is affected well cephalad near the median line between the tori longitudinalis. Behind the valve there is a sudden dorsal expansion containing a moderate cephalad protrusion of the cerebellar ven. tricle, which latter is connected by a dorsally elongated strait with the fourth ventriclc. The posterior part of the cerebellum is free and directed obliquely dorso-caudad, and is Hattened somewhat. The caudad protrusion of the ventricle thus becomes a mere line or is indicated only by the fused granular zones of the dorsal pnd ventral lamina. The lateral lobes of the cerebellum are very large.

In the buffalo-fish, Carpiodes, the cerebellum has a strong but not exaggerated development. The optic lobes, in consequence, are thrust cephalad and moderately dilated. The volvula is enormously developed and thrust forward. Its most remarkable peculiarity is that cephalad it becomes bifurcate. The dorsal lamina is fused with the ventral for much of its length, and the granular portion of the dorsal lamina is present only near the tip. The lamina becomes frec caudad and unites with the velum near the median line, as in the carp, though the union does not take place so far within the optic lobes and the tori extend far out on the velum.

In the region of the valve the lower lamina is greatly thickened. Except that the cephalad diverticle of the cere- 
bellar ventricle is somewhat larger; the remainder of the cerebellum is precisely as in the carp.

In the older individuals the great lateral expansion of the volvula is remarkable.

The extreme in this type of cerebellar differentiation is reached in the black horse, Cycleptus elongatus. In this case the optic lobes are thrust far cephalad over the cerebrum and expanded laterally like a hood. The tectum is wedged apart and the two tori are connected by a wide stretch of thin membrane only. The volvula is enormous, and consists of a central and two lateral lobes, in which the simple fold, which is the real source of the structure, is effectually obscured. The lateral lobes are pushed cephalad as divergen tuberosities. The appearance is as though these bodies had been formed by excessive lateral growth, which, among other things, had removed the granular layer entirely from the dorsal lamina and then crumpled the whole organ by lateral pressure. The middle lobe is morphologically the ventral lamina, which is thrust between the the two moities of the dorsal lamina.

This explanation solves the apparently unreconcilable conditions. The lateral lobes or severed portions of the dorsal lamina of the volvula extend far caudad of the point where the ventral lamina emerges as the roof of the fourth ventricle or vermiform portion of the cerebellum.

The presence of these two latero-caudal excrescences on either side of the median portion of the cerebellum is the obvious external cause of a median infolding of its dorsal roof, which is indicated even in the external vicw by the groove seen in Fig. 4, Plate XIX. In transverse sections the fold is seen to be an exceedingly deep one, though the edges coalesce completely.

The remainder of the cerebellum is as in the carp, except that the mode of connection with the medulla is modified by the lateral pockets containing the divaricated caudal protru. sions of the volvula. 
The cat-fish group presents more remarkable variations, which have been explained in detail by C. Judson Herrick.

In the drum the most remarkable peculiarity of the midregion of the brain is its relative shortness; the cerebellum is crowded far dorsad and lies perched, as it were, between the trigeminal lobes and the vertically elongate optic lobes. The great dorsal elevation and corresponding shortening of the optic lobes could not fail to exert a greatly modifying influence on the volvula, which in these fishes is very large. The result is seen in a curious multiple folding of the dorsal lamina in the frontal plane; so that successive lobes appear in transverse section. The remainder of the cerebellum shows no other effect of the compression than that exhibited in its position and a slight cephalo-dorsal protuberance.

The examples cited are sufficient to show that the most divergent types may easily be reduced to a single funda. mental form.

The cranial nerves have not been carefully studied in this connection, because of an exegency of publication, nor has there been opportunity to compare the papers of Prof. Wright on the cranial nerves of the cat fish. In the cat fish the exaggerated development of the trigeminal system is well illustrated in the earlier installment of this series, by $\mathrm{C}$. Judson Herrick.

In the drum (Haploidonotus) the following relations prevail: The vagus consists of two nearly equal branches, one of which springs from the caudal portion of the vagal tuberosity, while the other is derived from the extreme cephalic portion, and both are apparently derived from nearly the same dorso-ventral level. The two branches remain distinct for some distance, so that the cephalad root has an independent course, nearly twice as long as that of its fellow. At their union a more or less distinct ganglion is developed. From the latter the small nerve of the lateral line arises. A visceral branch and a branch probably supplying the pectoral fin-muscles follow, and then five branches to the gills, the 
caudal one dividing peripherally. The ninth nerve is much smaller than either branch of the vagus, and arises from the caudo-ventral aspect of the very tumid trigeminal lobe, a short distance caudad of the eighth. It soon receives a small anastamosing branch from the cephalic root of the vagus, which returns to the latter a little farther peripherad, but proximad of the ganglion. The distribution of the ninth is as described in the cat fish.

'The eighth has two distinct roots, but the cephalic branch is closely associated with the seventh, which is distinct from the fifth beyond Gasser's ganglion, and is distributed to the opercular and gular regions.

At its roots the fifth nerve is composed of three chief divisions, but beyond the ganglion there are five, the most dorsal of which is the trigeminal accessory nerve of the lateral line.

The sixth is small, and no separate root was found. The third and fourth are small, but normal, and the remaining nerves offer no peculiarities.

\section{P'LATE XIX.}

Fig. 1. Dorsal view of the brain of the buffalo-fish, Carpiodes tumidus, B. and G. L.z. G., vagal lobes; VIIl, eighth nerve; Ma. l., mesaxial lobe of the cerebrum; ("ul. l., cuneate lobe; I. l., lateral lobe; Op., optic nerve.

Fig: $\therefore$ Lateral view of the sane brain. Myp., hypophysis; $F$. or., occipital fissure: $F .5 \% l$, Sylvian tissure; 1 id., dorsal root of cephalic division of trigeminus; $r+$. . ventral division of the same; $\checkmark$... caudal trigeminus.

Figrs. .;.j. Three views of the brain of the black-horse, Cycleptus elongarus. IIr., hypophysis; $T$. cin., tuber cinereum; i'g. l., vagal lobe; IIpa., hypoaria.

Figs. ti-.. Laterill and dorsal views of the hrain of the gizzardshad, Dorosoma crepidianum.

Fig. s. Dorsal view of the brain of the moon-eye, Hyodon tergisus. The hemispheres are divaricated and deprived of the pallium.

Figrs. :1-11. Three views of the brain of the common eel.

PLATF, XX.

A series of transections of the brain of the black-horse; Cycleptus elongatus. A description of histological details will be given in a subsequent paper. 
Fig. 1 . Section at the union of the olfactoria with the rhinalic aspect of the hemispheres. (1). n.. optic nerve.

Fig. $\therefore$ Section somewhat caudad of the above. I.at. I., lateral lobe: Mest. l., mesaxial lobe: fi. rhin., rhinalis fissure.

Fig. S. Section cephalad of the dectssation of the optic nerves. The cerchrum is here overarched by the mesencephalon and the volvula. Kif. l., hippocampal lobe; in/i.., volvula cerebelli.

Fig. 7. Section at the decussation of the optic nerves. Torws long., torus longitudinalis: $\mathrm{Mr} m \mathrm{~m} /$. tert., the tela tecti or membranous portion of the tectum opticum.

fig. is. Section through the prithalamus, pre. the

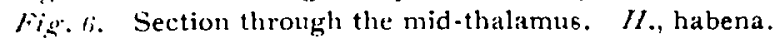

Fig. : Section cephalad to hypoaria. M. b.. Meynert's bundle.

Fig.s. Section through post-thalmus.

Fig. a. Section at the caudal level of the hypoaria. Region of mesencephalic decussations. $A q . S$. aqueduct of Sylvius.

Fig. 10. Section at the beginning of the cerebellum.

Figs. 11-1.x. Successive sections through the medulla and cerebellum. Description will be deferred to subsequent installment.

\section{PLATE XXI.}

Figs. $1-1$. Sections through the medulla of the black-horse, continuing the series of Plate XX. I.b. trigem., trigeminal lobe; L. i'agi, vagal lobes or tubers. Details will be given in later installment.

Figs. 4... Transections through the olfactory crura and cerebrum. Fig. 4 is some distance cephalad of Fig. 5 , and on the opposite (left; side.

Figrs. $i-11 \%$. Transectious of the brain of Dorosoma.

Fig. $\therefore$. Section at the anterior commissure.

Fig. $\therefore$. Section at the superior commissure.

Fig. :\%. Section at the exit of the third nerve.

Fig. 11\%. Section at the caudal level of the optic loles to illustrate the great induplication of the cerebellum along the median (line at a). The suppressed lateral ventricle, or reccssus lateralis, with its membranous lateral walls is indicated at ientr. lat. revelel. 
Journal of Comparative Neurology, Vol. I.

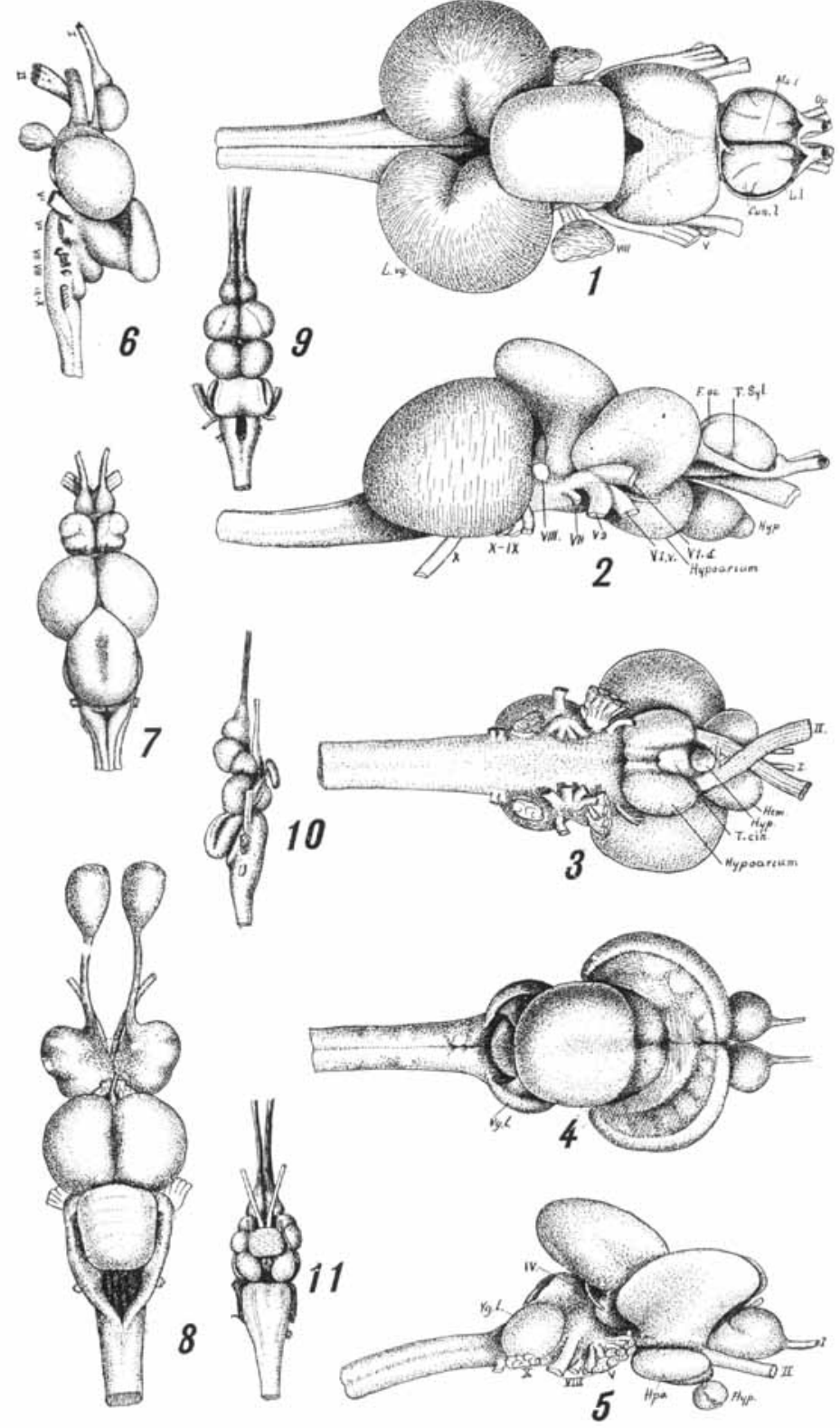



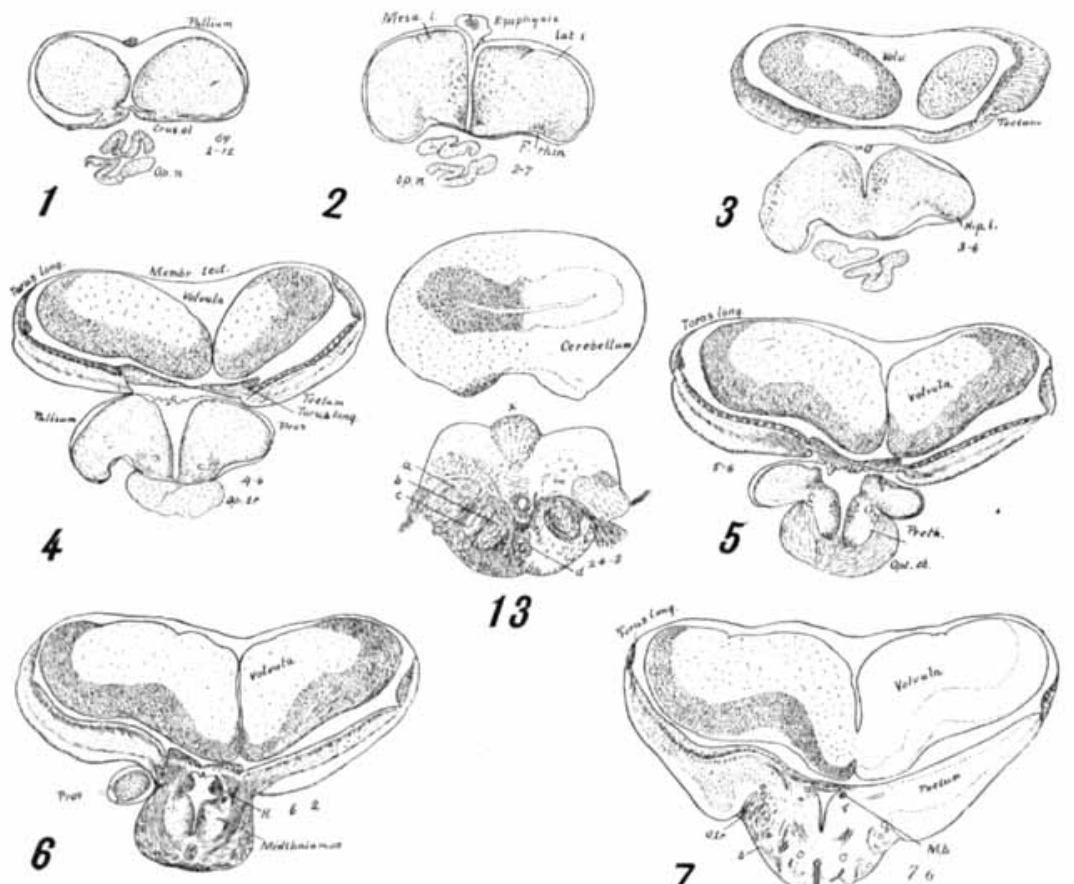

13
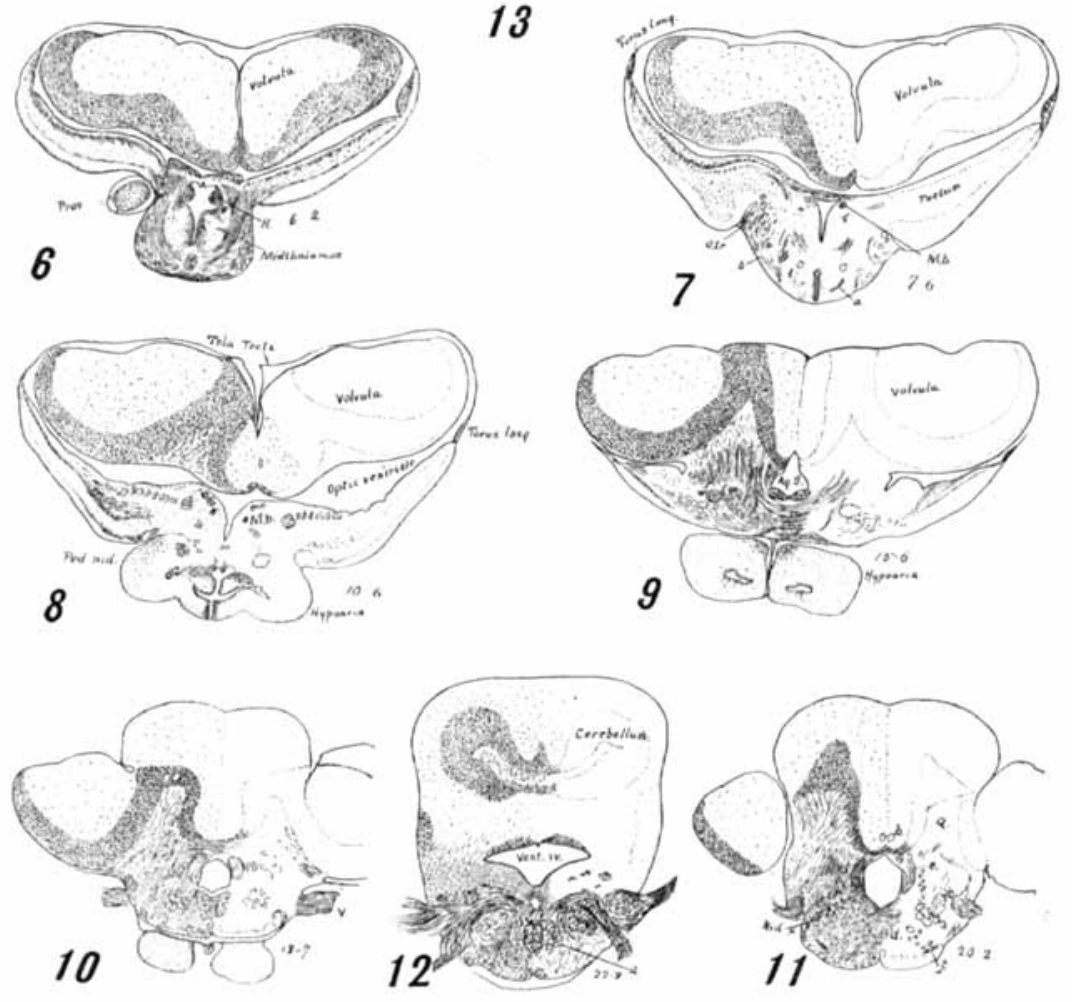


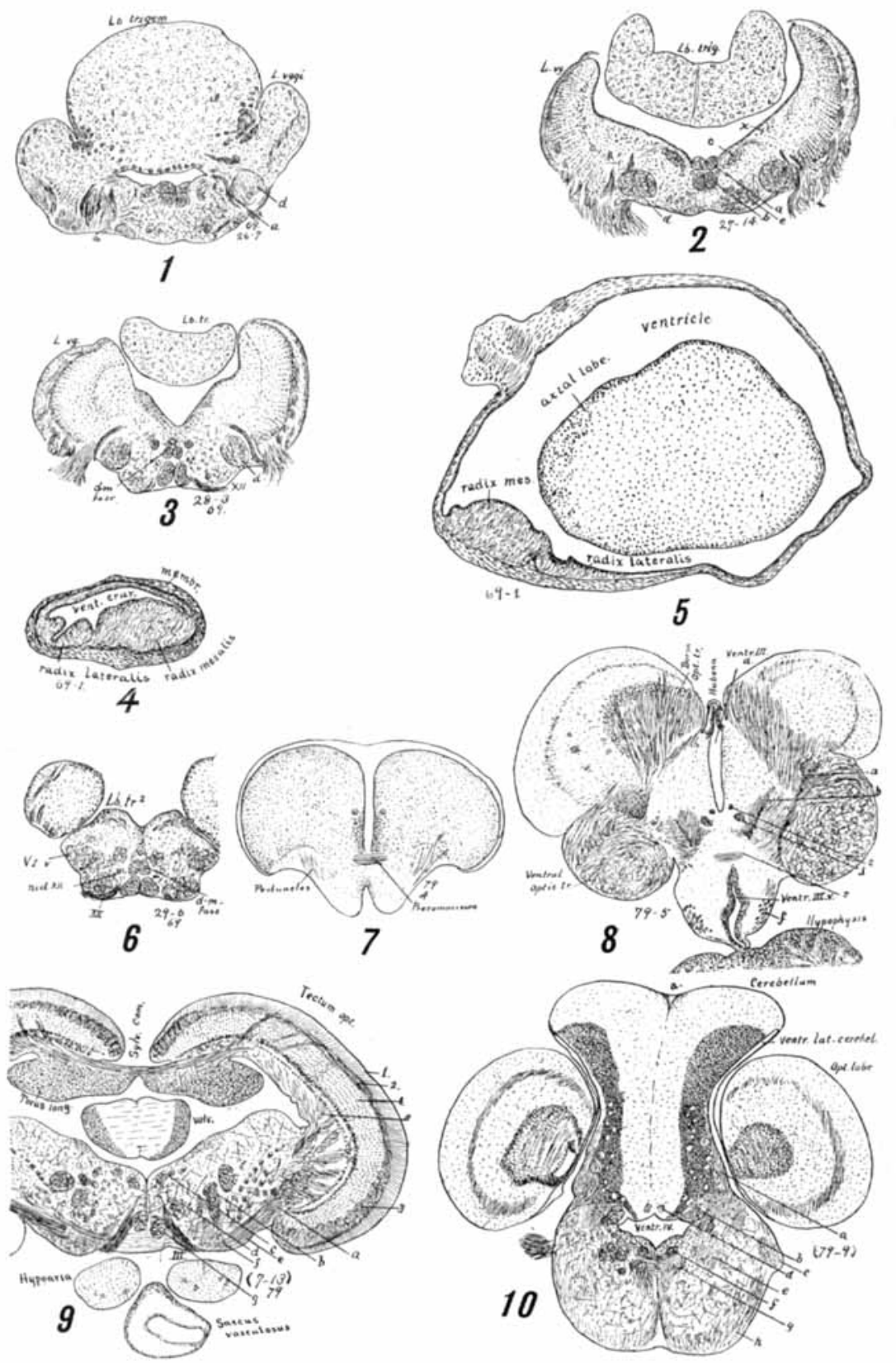


Journal of Comparative Neurology, Vol. I.
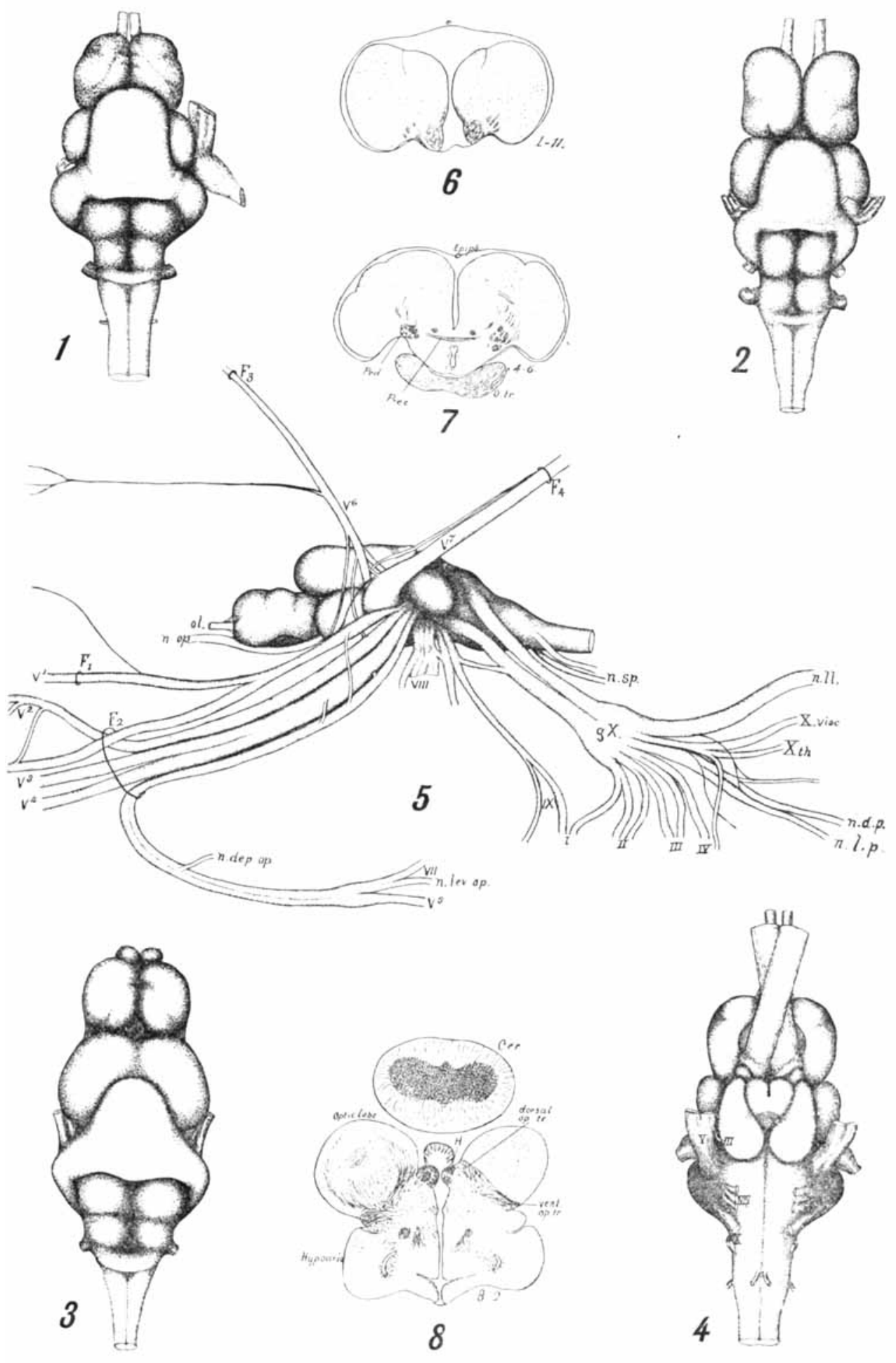